\title{
The binding characteristics of isoniazid with copper-zinc superoxide dismutase and its effect on enzymatic activity
}

\author{
Nana Du', Liangquan Sheng ${ }^{1,2^{*}}$, Zhaodi Liu', Xiaojuan $\mathrm{Hu}^{1,2}$, Huajie $\mathrm{Xu}^{1}$ and Shuisheng Chen ${ }^{1}$
}

\begin{abstract}
Background: Isoniazid (INH) is front-line anti-tuberculosis (TB) drugs, which are usually prescribed to TB patients for a total period of 6 months. Antituberculosis drug-induced hepatotoxicity (ATDH) is a serious adverse reaction of TB treatment. It is reported that INH-induced hepatotoxicity is associated with oxidative stress. Superoxide dismutase (SOD, EC 1.15.1.1) is the key enzyme for the protection of oxidative stress, which catalyzes the removal of superoxide radical anion, thereby raising the need to better understand the interaction between INH and SOD.

Results: The experimental results showed that the fluorescence intensity of $\mathrm{Cu} / \mathrm{Zn}-\mathrm{SOD}$ regularly decreased owing to form a 1:1 INH-SOD complex. According to the corresponding association constants ( $K_{\text {SV }}$ ) between INH and SOD obtained from Stern-Volmer plot, it is shown that values of $K_{\mathrm{A}}$ are $1.01 \times 10^{4}, 5.31 \times 10^{3}, 3.33 \times 10^{3}, 2.20 \times 10^{3} \mathrm{~L} \cdot \mathrm{mol}^{-1}$ at four different temperatures, respectively. The binding constants, binding sites and the corresponding thermodynamic parameters $\left({ }^{\Delta} H,{ }^{\Delta} G\right.$ and $\left.{ }^{\Delta} S\right)$ were calculated. A value of $3.93 \mathrm{~nm}$ for the average distance between $\mathrm{INH}$ and chromophore of Cu/Zn-SOD was derived from Förster theory of non-radiation energy transfer. The conformational investigation showed that the presence of $\mathrm{INH}$ resulted in the microenvironment and conformational changes of Cu/Zn-SOD. In addition, Effects of INH on superoxide dismutase activity was examined.
\end{abstract}

Conclusions: The results show that the hydrogen bonding and van der Waals forces play major roles in stabilizing the 1:1 INH-SOD complex. After addition of INH during the range of the experiment, the conformation and microenvironment of Cu/Zn-SOD are changed, but the activity of Cu/Zn-SOD is not changed.

Keywords: Superoxide dismutase, Isoniazid, Interaction, Antioxidation

\section{Background}

Tuberculosis (TB) is one of the leading causes of death due to a single disease, accounting for up to 2 million lives each year [1]. Isoniazid (INH) is the foremost first-line antibiotic used to treat $\mathrm{TB}$, which continues to be the cornerstone of all antituberculosis regimens and remains the only agent recommended for tuberculosis chemoprophylaxis for children [2].

Despite numerous and intensive studies, we have a limited knowledge of the action mechanism of INH [3-6]. The consensus opinion is that in the presence of a slow flux of $\mathrm{H}_{2} \mathrm{O}_{2}$ or superoxide, KatG converts INH

\footnotetext{
* Correspondence: shengla@fync.edu.cn

${ }^{1}$ College of Chemistry and Chemical Engineering, Fuyang Normal College, Fuyang 236041, People's Republic of China

${ }^{2}$ College of Chemistry and Chemical Engineering, Anhui University, Hefei 230039, People's Republic of China
}

into a radical species which is subsequently coupled to $\mathrm{NADH}$ to form an INH-NAD(P) adduct. The INH-NAD adduct is a potent inhibitor of $M t b$ InhA, an enoyl reductase required for the elongation steps in mycolic acid biosynthesis $[7,8]$. It has been recently suggested that the superoxide reactivity affects antitubercular activity of INH to some extent, and thereby raises the needs to better understand the interaction between INH and superoxide [9].

Furthermore, with increasing occurrence of TB all over the world, a growing number of patients may be at risk for severe adverse drug reactions (ADRs) such as antituberculosis drug-induced hepatotoxicity (ATDH) when treated with antituberculosis chemotherapy $[10,11]$. ATDH can be fatal if it is not recognised at an early stage, after which therapy should be interrupted timely. Moreover, ATDH has a negative impact on 
therapy adherence, decreases success rates of treatment and eventually increases treatment failure, relapse or the emergence of drug resistance. The occurrence of hepatotoxicity related to INH has been well-defined [12] and shown to increase as a result of drug-drug pharmacokinetic or pharmacodynamic interactions [13]. It is generally acknowledged that INH-induced hepatotoxicity is associated with oxidative stress [14].

Superoxide dismutase (SOD, EC 1.15.1.1) is an antioxidant enzyme in animals, plants, fungi and bacteria, which catalyzes the removal of superoxide radical anion $\left(\mathrm{O}_{2}^{-} \bullet\right)$ to hydrogen peroxide $\left(\mathrm{H}_{2} \mathrm{O}_{2}\right)$ that can be subsequently converted to water by the enzyme catalase $[15,16]$. Therefore, it is the key enzyme for the protection of oxidative stress and could be a suitable candidate drug to protect liver from ATDH [17-19]. To better understand the protective mechanism of SOD, the interaction between SOD and INH should be investigated.

Protein-drug interaction is a hot topic in fields of medicine, chemistry and biology. Also, due to the effects on the drug of pharmacokinetics when bounded to protein, there is an increasing interest in protein from clinical and pharmaceutical perspectives [20-22]. Furthermore, the binding of drugs to protein in vitro is considered as a model in protein chemistry to study the binding behavior of protein. Consequently, the investigation of the binding between drugs and SOD is of fundamental importance in pharmacology and pharmacodynamics. In addition, the analysis of the interaction between SOD and small drug molecules is interesting to some extent, because the binding of specific small molecules to SOD has only been characterized in detail for a few examples $[23,24]$.

In this paper, the interaction between $\mathrm{INH}$ and $\mathrm{Cu}$ / $\mathrm{Zn}$-SOD has been investigated with fluorescence and ultraviolet spectroscopy. The binding mechanism, binding constants, binding sites and binding distance were obtained. The nature of the binding force was analyzed based on the thermodynamic parameters. Also, the effects of INH on the conformation of $\mathrm{Cu} / \mathrm{Zn}$-SOD were examined by synchronous fluorescence and three-dimensional fluorescence spectroscopy. What is more, the effects of INH on the activity of $\mathrm{Cu} / \mathrm{Zn}$-SOD were also explored. We hope that this work can provide useful information for pharmacology of INH.

\section{Results and discussion}

\section{Effects of INH on Cu/Zn-SOD fluorescence}

The fluorescence of $\mathrm{Cu} / \mathrm{Zn}$-SOD comes from the tryptophan, tyrosine and phenylalanine residues [25]. With $280 \mathrm{~nm}$ of excited wavelength, the maximum emission peak of $\mathrm{Cu} / \mathrm{Zn}$-SOD could be achieved at $306 \mathrm{~nm}$ [26]. Figure 1 shows the fluorescence spectra of $\mathrm{Cu} / \mathrm{Zn}-\mathrm{SOD}$ upon the addition of INH. Obviously, with the increasing concentration of $\mathrm{INH}$, the fluorescence intensity

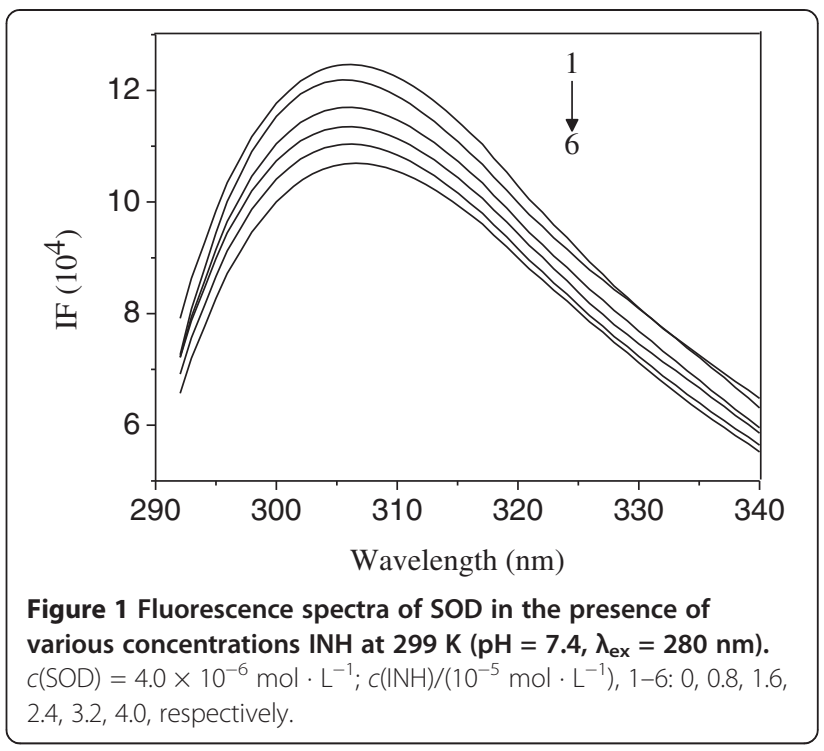

decreased regularly but without significant position-shift. The strong quenching of the fluorescence clearly indicated that the interaction between INH and $\mathrm{Cu} / \mathrm{Zn}$-SOD changed the microenvironment of chromophore or the tertiary structure of $\mathrm{Cu} / \mathrm{Zn}-\mathrm{SOD}$.

\section{The quenching mechanism of $\mathrm{Cu} / \mathrm{Zn}-\mathrm{SOD}$ fluorescence by} INH

Fluorescence quenching refers to any processes which decrease the fluorescence intensity of a sample such as excited state reactions, energy transfers, ground-state complexes formation and collisional process [27]. Mechanisms of quenching are usually divided into dynamic quenching and static quenching [27]. Different quenching mechanisms can be distinguished by their different dependence on temperature and excited-state life time. As higher temperatures could result in larger diffusion coefficients, the dynamic quenching constants are expected to be larger with an increasing temperature. In contrast, the increase of temperature is likely to result in a decreased stability of complexes; thus, the values of static quenching constants are expected to be smaller. In the present work, the fluorescence-quenching spectra of $\mathrm{Cu} / \mathrm{Zn}-\mathrm{SOD}$ with presence of different concentrations of INH at four different temperatures (the temperatures used were 292, 295, 299 and $303 \mathrm{~K}$ ) were measured. The fluorescence quenching was usually analyzed by the well-known Stern-Volmer equation [28,29]:

$$
F_{0} / F=1+K_{\mathrm{SV}}[\mathrm{Q}]=1+K_{q} \tau_{0}[\mathrm{Q}]
$$

where $F_{0}$ and $F$ are fluorescence intensities of $\mathrm{Cu} / \mathrm{Zn}$-SOD in the absence and presence of the quencher (INH), respectively, $K_{\mathrm{q}}$ is the quenching rate constant, $K_{\mathrm{SV}}$ is the Stern-Volmer constant, $\tau_{0}$ is the average life time of the 
molecule without quencher and the fluorescence lifetime of the biopolymer is $10^{-8} \mathrm{~s},[\mathrm{Q}]$ is the quencher concentration.

Figure 2 shows the Stern-Volmer plots of the $\mathrm{Cu} / \mathrm{Zn}$ SOD quenching fluorescence by INH. The values of $K_{\mathrm{SV}}$ obtained from the slop of plots are $5.06 \times 10^{3}, 4.45 \times 10^{3}$, $3.89 \times 10^{3}$ and $3.41 \times 10^{3} \mathrm{~L} \cdot \mathrm{mol}^{-1}$, respectively. It is evident that the $K_{\mathrm{SV}}$ values are inversely correlated with temperature (inset in Figure 2), and $K_{\mathrm{q}}$ is much greater than the value of the maximum scatter collision quenching constant $\left(2.0 \times 10^{10} \mathrm{~L} \cdot \mathrm{mol}^{-1} \cdot \mathrm{s}^{-1}\right)$, which indicates the static mechanism of quenching and reveals that the fluorescence quenching is caused by specific interaction and complex formation between $\mathrm{Cu} / \mathrm{Zn}$-SOD and INH molecules [27].

\section{Calculation of binding parameters}

For static quenching, the following equation was employed to calculate the binding constant and binding sites [30,31]:

$$
\log \frac{F_{0}-F}{F}=\log K_{\mathrm{A}}+n \log [\mathrm{Q}]
$$

where $F_{0}, F$ and $[\mathrm{Q}]$ are the same as in Eq.(1), $K_{\mathrm{A}}$ and $n$ are the binding constant and the number of binding sites respectively, $K_{\mathrm{A}}$ and $n$ can be obtained from the plots of $\log \left[\left(F_{0^{-}}-F\right) / F\right]$ vs. $\log [\mathrm{Q}]$ for the INH-SOD system at four temperatures. The calculated results are shown in Table 1. The results show that $K_{\mathrm{A}}$ decreases with the increase of temperature, which probably indicates the formation of a compound partially decomposes at higher temperatures. The value of $n$ is equal to approximately 1 , indicating the involvement of a single binding site in the INH-SOD interaction.

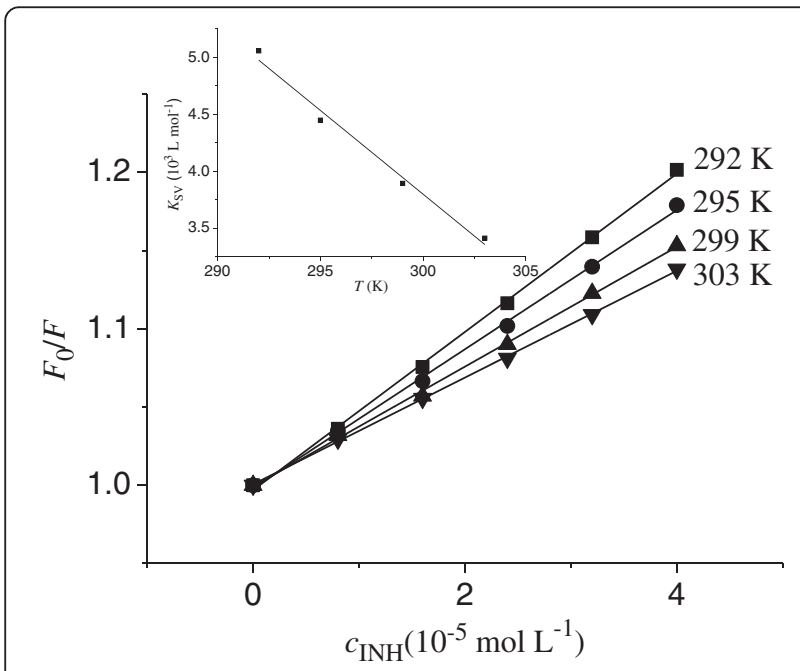

Figure 2 Stern-Volmer plots for the quenching of SOD by INH at four different temperatures, $(\mathrm{pH}=7.4)$. Inset: $K_{S V}{ }^{-T}$.
In order to confirm the probable quenching mechanism of $\mathrm{Cu} / \mathrm{Zn}$-SOD by INH, the absorption spectra of $\mathrm{Cu} / \mathrm{Zn}$ SOD in the presence and absence of INH at $303 \mathrm{~K}$ were recorded and presented in Figure 3. As seen in Figure 3, with the addition of INH the absorbance peak around $213 \mathrm{~nm}$, which was mainly caused by the transition $\pi-\pi^{*}$ of peptide bonds in SOD decreased regularly with peak red-shift (from 213 to 220). Thus, the ground state complex between SOD and INH was possibly formed. The absorbance peak caused by the transition $\pi-\pi^{*}$ gets red-shifted with the increase of solvent polarity, so we can draw a conclusion that the polarity of the microenvironment of SOD is altered, leading to a conformational change that the peptide strands of SOD are extended and its hydrophobicity is decreased [28,30,31].

According to literature $[32,33]$, when one small organic molecule binds to biological macromolecule, the relationship between absorbance intensity of biological macromolecules and the small organic molecule concentration can be written as follows:

$$
\left(A_{0}-A\right)^{-1}=A_{0}^{-1}+K_{A}^{-1} A_{0}^{-1}[\mathrm{Q}]^{-1}
$$

where $A_{0}$ and $A$ are the absorbance intensities of $\mathrm{Cu} / \mathrm{Zn}$ SOD in the absence and presence of the INH, respectively, $K_{\mathrm{A}}$ and $[\mathrm{Q}]$ are the binding constant and INH concentration. As shown in the inset in Figure 3, plot of $1 /\left(A_{0}-A\right)$ against $1 /[\mathrm{Q}]$ gives a straight line, the correlation coefficient of which is 0.9986 and the binding constant $\left(K_{\mathrm{A}}\right)$ is equal to $2.32 \times 10^{3} \mathrm{~L} \cdot \mathrm{mol}^{-1}$. The results further prove that only one molecule of INH binds $\mathrm{Cu} / \mathrm{Zn}$-SOD.

\section{Thermodynamic analysis and intermolecular forces}

The intermolecular forces of interaction between small molecules and biomolecules mainly include hydrogen bonding, van der Waals forces, electro static forces and hydrophobic forces. Within a small temperature range, the enthalpy of interaction can be regarded as a constant leading to the following equations $[34,35]$ :

$$
\begin{aligned}
& \ln \left(K_{\mathrm{A} 2} / K_{\mathrm{A} 1}\right)=\Delta H\left(1 / T_{1}-1 / T_{2}\right) / R \\
& \Delta G=\Delta H-T \Delta S \\
& \Delta S=-(\Delta G-\Delta H) / T
\end{aligned}
$$

where $R$ is the gas constant, $T$ is the absolute temperature and $K_{\mathrm{A}}$ is the apparent binding constant at corresponding temperature $T$. If $\Delta S>0$ and $\Delta H>0$, the main force of interaction is the hydrophobic force, if $\Delta S>0, \Delta H<0$, the main force is electro static attraction, if $\Delta S<0, \Delta H<0$, the main force includes both van der Waals forces and hydrogen bonding. Table 1 shows the values of $\Delta H, \Delta S$ and $\Delta G$ at four temperatures. The negative values of $\Delta G$ reveal that the interaction process is spontaneous. As $\Delta S<0$ and $\Delta H<0$, which indicates that 
Table 1 Binding parameters, number of binding sites and thermodynamic parameters of INH-SOD at four temperatures

\begin{tabular}{|c|c|c|c|c|c|c|}
\hline$T(\mathrm{~K})$ & $K_{\mathrm{SV}}\left(\mathrm{L} \cdot \mathrm{mol}^{-1}\right)$ & $K_{\mathrm{A}}\left(\mathrm{L} \cdot \mathrm{mol}^{-1}\right)$ & $n$ & $\Delta G\left(\mathrm{~kJ} \cdot \mathrm{mol}^{-1}\right)$ & $\Delta H\left(\mathrm{~kJ} \cdot \mathrm{mol}^{-1}\right)$ & $\Delta S\left(\mathrm{~J} \cdot \mathrm{mol}^{-1} \cdot \mathrm{K}^{-1}\right)$ \\
\hline 292 & $5.06 \times 10^{3}$ & $1.01 \times 10^{4}$ & 1.069 & $-22.38(s=1.69)$ & $-105.70(s=9.54)$ & $-284.66(s=18.50)$ \\
\hline 295 & $4.45 \times 10^{3}$ & $5.31 \times 10^{3}$ & 1.019 & $-21.04(s=1.73)$ & & $-286.31(s=15.67)$ \\
\hline 299 & $3.89 \times 10^{3}$ & $3.33 \times 10^{3}$ & 0.995 & $-20.16(s=1.54)$ & & $-285.42(s=19.92)$ \\
\hline 303 & $3.41 \times 10^{3}$ & $2.20 \times 10^{3}$ & 0.999 & $-19.36(s=1.26)$ & & $-284.29(s=19.31)$ \\
\hline
\end{tabular}

the interaction between INH and $\mathrm{Cu} / \mathrm{Zn}-\mathrm{SOD}$ is mainly due to hydrogen bonding and van der Waals forces $[34,35]$.

\section{Energy transfer between $\mathrm{Cu} / \mathrm{Zn}-\mathrm{SOD}$ and INH}

The energy transfer in biochemistry is important, because the efficiency of transfer can be used to evaluate the distance between the ligand and the chromophore in protein. The overlap of the UV-Vis absorption spectrum of INH with the fluorescence emission spectrum of $\mathrm{Cu} / \mathrm{Zn}-\mathrm{SOD}$, as is shown in Figure 4. According to Förster nonradiative energy-transfer theory, the efficiency of energy transfer is $E$, the critical distance for $50 \%$ energy transfer is $R_{0}$, and the actual distance of separation is $r$. These values were calculated by Eqs. $(7,8,9)$ [35-37]:

$$
\begin{aligned}
& E=1-\frac{F}{F_{0}}=\frac{R_{0}^{6}}{R_{0}^{6}+r^{6}} \\
& R_{0}^{6}=8.8 \times 10^{-25} K^{2} \Phi N^{-4} J
\end{aligned}
$$

where $r$ is the distance from the ligand to the chromophore of the protein, and $R_{0}$ is the Förster critical

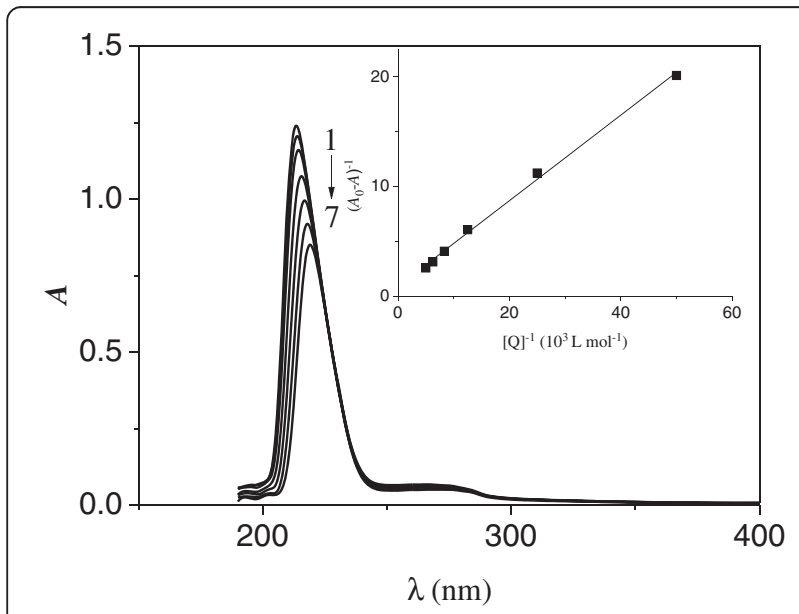

Figure 3 UV-Vis absorption spectra of SOD in the absence and presence of $\mathrm{INH}$ system $(\mathrm{pH}=7.4, \mathrm{~T}=303 \mathrm{~K})$. $c(\mathrm{SOD})=4.0 \times 10^{-6} \mathrm{~mol} \cdot \mathrm{L}^{-1} ; C(\mathrm{INH}) /\left(10^{-5} \mathrm{~mol} \cdot \mathrm{L}^{-1}\right), 1-7: 0,2,4,8$, $12,16,20$, respectively. Insert: $\left(A_{0^{-}} A\right)^{-1}$ vs. [Q] ${ }^{-1}$. distance at which $50 \%$ of the excitation energy is transferred to the acceptor.

$$
J=\frac{\sum F(\lambda) \varepsilon(\lambda) \lambda^{4} \Delta \lambda}{\sum F(\lambda) \Delta \lambda}
$$

where $F(\lambda)$ is the fluorescence intensity of the donor at the wavelength range $\lambda$, and $\varepsilon(\lambda)$ is the molar absorption coefficient of the acceptor at wavelength $\lambda$. In this case, $K_{2}=2 / 3, \mathrm{~N}=1.336$ and $\Phi=0.13$ [36]. According to the equation (7), (8), (9), we could calculate that $J=2.3 \times 10^{-13} \mathrm{~cm}^{3} \cdot \mathrm{L} \cdot \mathrm{mol}^{-1}, E=0.022, R_{0}=2.58 \mathrm{~nm}$, and $r=3.93 \mathrm{~nm}$. The binding distance between INH and $\mathrm{Cu} / \mathrm{Zn}-\mathrm{SOD}$ is shorter than $7 \mathrm{~nm}$, which indicates that the energy transfer from $\mathrm{Cu} / \mathrm{Zn}-\mathrm{SOD}$ to INH occurs with high possibility [35-37]. It is also suggested that the binding of INH to $\mathrm{Cu} / \mathrm{Zn}-\mathrm{SOD}$ is conducted through energy transfer, which is consistent with a static quenching mechanism.

\section{Conformation investigation of $\mathrm{Cu} / \mathrm{Zn}-\mathrm{SOD}$}

The influence of INH on conformational changes of $\mathrm{Cu} / \mathrm{Zn}-\mathrm{SOD}$ was assessed by synchronous fluorescence. Synchronous fluorescence measurement provides information about the molecular microenvironment in the vicinity of the fluorophore functional groups [38]. When the wavelength shift $(\Delta \lambda)$ between the emission and

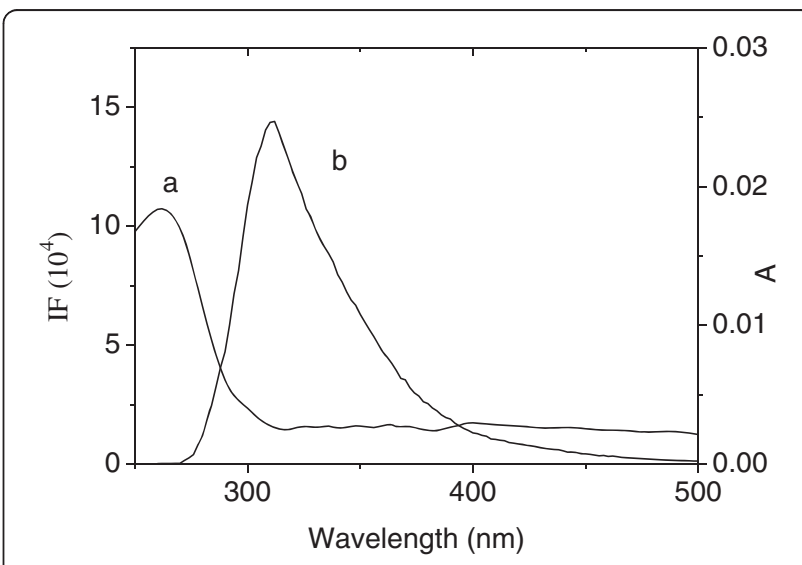

Figure 4 Spectral overlap of UV-Vis absorption spectrum of INH (a) with the fluorescence emission spectrum of SOD (b). $c(S O D)=c(I N H)=4.0 \times 10^{-6} \mathrm{~mol} \cdot \mathrm{L}^{-1}(\mathrm{pH}=7.4, T=303 \mathrm{~K})$. 
excitation wavelengths was stabilized at 20 or $80 \mathrm{~nm}$ [39], the synchronous fluorescence gives the characteristic information of tyrosine or tryptophan residues, respectively. Figure 5A and Figure 5B show the effects of INH on the synchronous fluorescence of $\mathrm{Cu} / \mathrm{Zn}-\mathrm{SOD}$. As seen in Figure 5, the fluorescence intensities of tryptophan residue and tyrosine residue decreased with the increase of the concentration of INH. The maximum emission wavelength of tyrosine residues does not undergo a significant shift in the investigated concentration range. In contrast, an obvious red shift was observed for tryptophan residues, which indicated that the polarity around tryptophan residues increased. In other words, tryptophan residues were placed in a less hydrophobic environment and were more exposed to the solvent.

In recent years, the three-dimensional fluorescence technique has been widely used, because it allows fluorescence characteristics to be acquired by changing the excitation and emission wavelengths simultaneously. We studied the conformational and microenvironmental changes of $\mathrm{Cu} / \mathrm{Zn}-\mathrm{SOD}$ by comparing the spectral changes in the absence and presence of INH, as shown

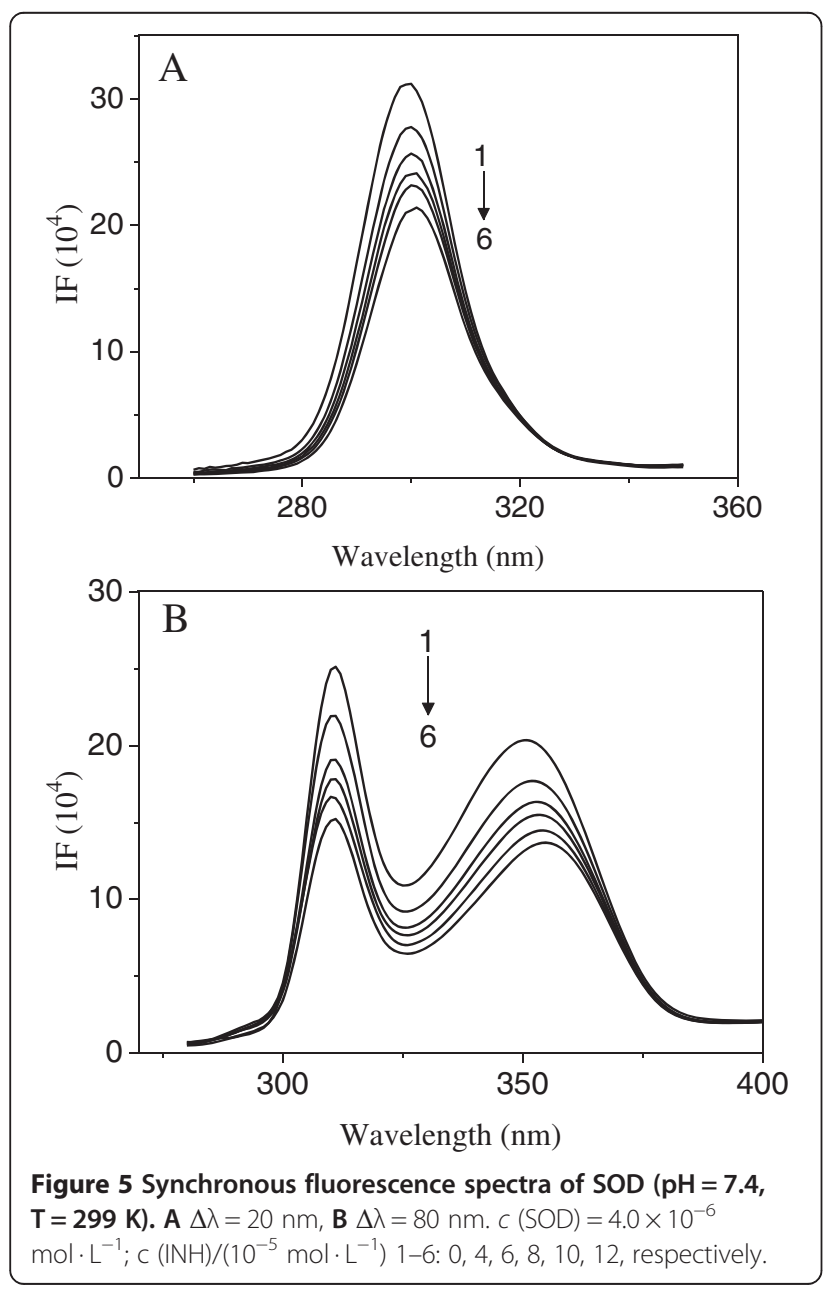

in Figure 6. In these figures, peak a is the Rayleigh scattering peak $\left(\lambda_{\mathrm{ex}}=\lambda_{\mathrm{em}}\right)$, the peak intensity of which increased with the addition of INH. A reasonable explanation may be that an INH-SOD complex formed after the addition of $\mathrm{INH}$, increased the diameter of the macromolecule, and thus enhanced the scattering effects [40]. Peak $b$ is the second-ordered scattering peak $\left(\lambda_{\text {em }}=2 \lambda_{\text {ex }}\right)$. Peak $1\left(\lambda_{\text {ex }}=280.0 \mathrm{~nm}, \lambda_{\text {em }}=306.0 \mathrm{~nm}\right)$ mainly reveals the spectral behavior of the Trp and Tyr residues since excitation of SOD at this wavelength mainly reveals their intrinsic fluorescence, and the fluorescence of the phenylalanine residue can be negligible [25]. Besides peak 1 , there is another strong fluorescence peak (peak 2, $\lambda_{\mathrm{ex}}=232.0 \mathrm{~nm}, \lambda_{\mathrm{em}}=306.0 \mathrm{~nm}$ ), which mainly exhibits the fluorescence spectral behavior of polypeptide backbone structures [40]. Both peaks were involved in




fluorescence quenching of $\mathrm{Cu} / \mathrm{Zn}$-SOD by INH to different degrees. By analyzing the intensity changes of peak 1 and peak 2, in the absence and presence of INH, the fluorescence intensity ratio of peak 1 to peak 2 is 1.16:1 and 1.18:1, respectively. All of these phenomena and analyses revealed that the binding of INH to SOD induced some microenvironmental and conformational changes in $\mathrm{Cu} / \mathrm{Zn}-\mathrm{SOD}$.

\section{Effects of INH on $\mathrm{Cu} / \mathrm{Zn}$-SOD activity}

The activity of $\mathrm{Cu} / \mathrm{Zn}$-SOD after the addition of INH was studied to investigate the effects of INH on superoxide dismutase activity. Figure $7 \mathrm{a}$ shows the relationship between antioxidant effect of INH-SOD and INH concentration. Figure $7 \mathrm{~b}$ shows the relationship between antioxidant effect of dissociative INH and its concentration. Due to antioxidant effect of INH in the range of the experiment, the antioxidation of INH-SOD was strengthened with increasing INH concentration. The enzyme activity was determined by subtracting the antioxidant effect of INH from antioxidant effect of INH-SOD (Figure 7c). The results show that the enzyme activity is almost the same throughout the experiment. The observation leads to the conclusion that the INH does not affect the activity of $\mathrm{Cu} / \mathrm{Zn}$-SOD.

\section{Experimental}

\section{Materials}

$\mathrm{Cu} / \mathrm{Zn}$-SOD was purchased from Doulai Biotechnology Company (Nanjing, China), INH was purchased from Taizhou Medical Corporation (Zhejiang, China). SOD was directly dissolved in redistilled water to prepare the stock solution $(0.12 \mathrm{mM})$, and the stock solution was kept in the dark at $0-4^{\circ} \mathrm{C}$. INH solution was obtained by dissolving it in redistilled water $(1.2 \mathrm{mM}) .0 .05 \mathrm{M}$ Tris- $\mathrm{HCl}$ buffer solution of $\mathrm{pH} 7.4$ and 8.2 were prepared. Other

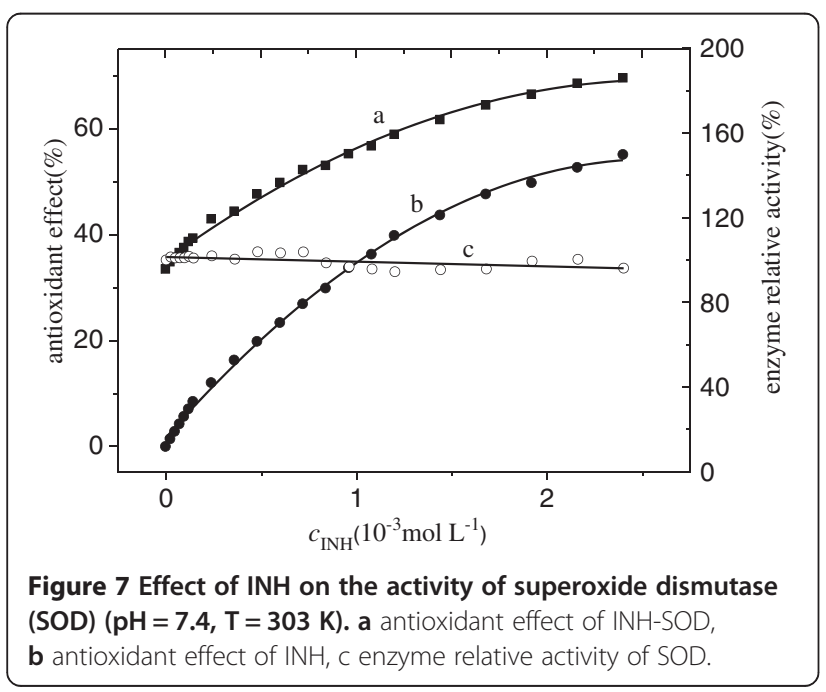

reagents are local products of analytical grade. The water used was redistilled and ion-free.

Fluorescence measurements were carried out in $1.0 \mathrm{~cm}$ quartz cells on a FluoroMax-4 spectrophotometer (Horiba, Japan) equipped with a thermostat bath. UV-vis spectra were recorded on an 8000A spectrophotometer (Beijing Purkinje General Corporation, China). All $\mathrm{pH}$ measurements were made using a pHS-3 digital pH-meter (Chengdu Sanke Instrument Corporation, China) with a combined glass electrode.

\section{Assay}

A $3.0 \mathrm{~mL}$ Tris- $\mathrm{HCl}$ (pH 7.4, $0.05 \mathrm{M}$ ) buffer solution containing $4 \mu \mathrm{M}$ SOD was titrated by successive additions of $1.2 \mathrm{mM}$ INH solution and the concentration of INH varied from 0 to $40 \mu \mathrm{M}$. Titrations were done manually by using the microinjectors. After reaction for $10 \mathrm{~min}$, fluorescence spectra were measured in the range of 290-450 nm at the excitation wavelength of $280 \mathrm{~nm}$. The fluorescence spectra were performed at four temperatures (292, 295, 299 and 303 K). The excitation and emission slits were $5 \mathrm{~nm}$.

The synchronous fluorescence spectra were recorded at $299 \mathrm{~K}$ from $260 \mathrm{~nm}$ to $350 \mathrm{~nm}$ (for tyrosine residues) at $\Delta \lambda=20$ and from 280 to 400 at $\Delta \lambda=80 \mathrm{~nm}$ (for tryptophan residues). The excitation and emission slits were10 $\mathrm{nm}$.

Three-dimensional fluorescence spectra of SOD were recorded at $299 \mathrm{~K}$ in the presence and absence of INH with an excitation wavelength in the range $230-300 \mathrm{~nm}$ and an emission wavelength in the range $260-500 \mathrm{~nm}$. The excitation and emission slits were $5 \mathrm{~nm}$.

A $3.0 \mathrm{~mL}$ Tris- $\mathrm{HCl}(\mathrm{pH} 7.4,0.05 \mathrm{M})$ buffer solution containing $4 \mu \mathrm{M}$ SOD was titrated by successive additions of $1.2 \mathrm{mM}$ INH solution and the concentration of INH varied from 20 to $200 \mu \mathrm{M}$. Titrations were done manually by using the microinjectors. After reaction for $10 \mathrm{~min}$ at $303 \mathrm{~K}$, absorption spectra of SOD-INH were recorded in the range 190-400 $\mathrm{nm}$.

The activity of $\mathrm{Cu} / \mathrm{Zn}$-SOD was assayed by using the pyrogallol autoxidation method. The assay mixture contained $5.0 \mathrm{ml}$ Tris- $\mathrm{HCl}(\mathrm{pH} 8.2,0.05 \mathrm{M})$ buffer, $0.1 \mathrm{mM}$ pyrogallol solution, $2.5 \mathrm{nM}$ SOD solution and different concentrations of INH. The concentration of INH varied from 0 to $2.4 \mathrm{mM}$. Absorption at $325 \mathrm{~nm}$ at $303 \mathrm{~K}$ against time was recorded using a spectrophotometer. The SOD activity was determined as pyrogallol autoxidation rate.

\section{Conclusions}

In this paper, the interaction between INH and SOD was studied using fluorescence and ultraviolet spectroscopy at different temperatures under imitated physiological conditions. The results show that the quenching 
mechanism of fluorescence of SOD by INH is a static quenching process. The binding constants, binding sites and the corresponding thermodynamic parameters $(\Delta H, \Delta G$ and $\Delta S$ ) were determined, which indicates that hydrogen bonding and van der Waals forces play a major role in the binding process. According to Förster theory of nonradiation energy transfer, the binding distance between $\mathrm{Cu} / \mathrm{Zn}$-SOD and INH is $3.93 \mathrm{~nm}$ and the energy transfer occurs between SOD and INH with high probability. UV-vis, synchronous fluorescence and three-dimensional fluorescence studies indicates that the interaction leads to a change in the conformation and microenvironment of $\mathrm{Cu} / \mathrm{Zn}$-SOD. Moreover, determination of SOD activity in different concentration INH leads to the conclusion that the binding of INH with SOD does not affect the activity of $\mathrm{Cu} / \mathrm{Zn}-\mathrm{SOD}$. This report has special significance in pharmacology and clinical medicine as well as methodology.

\section{Competing interests}

The authors declare that they have no competing interests.

\section{Authors' contributions}

ND made a significant contribution to acquisition of data, analysis and manuscript preparation. XH has made a substantial contribution to experimental design and data analysis. ZL and HX participated in partial experiments. LS made a significant contribution to experimental design, data analysis, and manuscript revision. SC participated in study design and manuscript revision. All authors read and approved the final manuscript.

\section{Acknowledgement}

This work was financially supported by the International Sea Area Resources Survey and Development of the 12th Five-year Plan of China (DY125-15-E-01), the Nature Science Foundation of China (20971024) and the Higher Education Institutions Key Nature Science Foundation of Anhui (kj2009A127)

Received: 17 April 2013 Accepted: 30 May 2013

Published: 6 June 2013

\section{References}

1. Iyawoo K: Tuberculosis in Malaysia: problems and prospect of treatment and control. Tuberculosis 2004, 84:4-7.

2. Prasad B, Singh S: LC-MS/TOF and UHPLC-MS/MS study of in vivo fate of rifamycin isonicotinyl hydrazone formed on oral co-administration of rifampicin and isoniazid. J Pharmaceut Biomed 2010, 52:377-383.

3. Verma RK, Mukker JK, Singh RSP, Kumar K, Verma PRP, Misra A: Partial biodistribution and pharmacokinetics of isoniazid and rifabutin following pulmonary delivery of inhalable microparticles to rhesus macaques. Mol Pharm 2012, 9:1011-1016.

4. Ràfols C, Bosch E, Ruiz R, Box KJ, Reis M, Ventura C, Santos S, Araújo ME, Martins F: Acidity and hydrophobicity of several new potential antitubercular drugs: isoniazid and benzimidazole derivatives. J Chem Eng Data 2012, 57:330-338.

5. Vilchèze $C$, Wang F, Arai M, Hazbón MH, Colangeli R, Kremer L, Weisbrod TR, Alland D, Sacchettini JC, Jacobs WR: Transfer of a point mutation in MT inhA resolves the target for isoniazid. Nat Med 2006, 12:1027-1029.

6. Argyrou A, Vetting MW, Blanchard JS: New insight into the mechanism of action of and resistance to isoniazid: interaction of mycobacterium tuberculosis enoyl-ACP reductase with INH-NADP. J Am Chem Soc 2007, 129:9582-9583.

7. Zhao XB, Yu SW, Magliozzo RS: Characterization of the binding of isoniazid and analogues to Mycobacterium tuberculosis catalaseperoxidase. Biochemistry 2007, 46:3161-3170.

8. Wahab HA, Choong YS, Ibrahim P, Sadikun A, Scior T: Elucidating isoniazid resistance using molecular modeling. J Chem Inf Model 2009, 49:97-107.
9. Ghiladi RA, Medzihradszky KF, Rusnak FM, Ortiz de Montellano PR: Correlation between isoniazid resistance and superoxide reactivity in Mycobacterium tuberculosis KatG. J Am Chem Soc 2005, 127:13428-13442.

10. Nicolas V, Michel FR, Alberto C, Florence D, Pierre D, Bernadette M, Laurent $N$, Jules D, Denis H: CYP2E1 genotype and isoniazid-induced hepatotoxicity in patients treated for latent tuberculosis. Eur J Clin Pharmacol 2006, 62:423-429.

11. Alma T, Martin JB, Wilbert HMP, Hennie MJR, Rob EA, Andŕe JAM, van der Ven PN, Dekhuijzen R: Isoniazid and its toxic metabolite hydrazine induce in vitro pyrazinamide toxicity. Int J Antimicrob Ag 2008, 31:577-580.

12. Yee D, Valiquette C, Pelletier M, Parisien I, Rocher I, Menzies D: Incidence of serious side effects from first-line antituberculosis drugs among patients treated for active tuberculosis. Am J Respir Crit Care Med 2003, 167:1472-1477.

13. Schaberg T, Rebhan K, Lode H: Risk factors for side effects of isoniazid, rifampin and pyrazinamide in patients hospitalized for pulmonary tuberculosis. Eur Respir J 1996, 9:2026-2030.

14. Yakup E, Tulay E, Hafize U, Habibe G, Tuncay A, Ethem E: Effect of vitamin C on oxidative liver injury due to isoniazid in rats. Pediatr Int 2010, 52:69-74.

15. McCord JM, Fridovich I: Superoxide dismutase. An enzymic function for erythrocuprein (hemocuprein). J Biol Chem 1969, 244:6049-6055.

16. Maurizi CP: Alzheimer's disease: roles for mitochondrial damage, the hydroxyl radical, and cerebrospinal fluid deficiency of melatonin. Med Hypotheses 2001, 57:156-160

17. Wang XF, Lv Y, Okamura T, Kawaguchi H, Wu G, Sun WY, Ueyama N Structure variation of mercury(II) halide complexes with different imidazole-containing ligands. Cryst Growth Des 2007, 7:1125-1133.

18. Hayakawa N, Asayama S, Noda Y, Shimizu T, Kawakami H: Pharmaceutical effect of manganese porphyrins on manganese superoxide dismutase deficient mice. Mol Pharm 2012, 9:2956-2959.

19. Axthelm F, Casse O, Koppenol WH, Nauser T, Meier W, Palivan CG. Antioxidant nanoreactor based on superoxide dismutase encapsulated in superoxide-permeable vesicles. J Phys Chem B 2008, 112:8211-8217.

20. Maji SK, Amsden JJ, Rothschild KJ, Condron MM, Teplow DB: Conformational dynamics of amyloid $\beta$-protein assembly probed using intrinsic fluorescence. Biochemistry-US 2005, 44:13365-13376.

21. $X u X L$, Zhang $L Y$, Shen DK, Wu H, Peng LL, Li JH: Effect of metal ion substitutions in anticoagulation factor I from the venom of Agkistrodon acutus on the binding of activated coagulation factor $\mathrm{X}$ and on structural stability. J Biol Inorg Chem 2009, 14:559-571.

22. Xu XL, Zhang LY, Luo ZF, Shen DK, Wu H, Peng LL, Song JJ, Zhang Y: Metal ions binding to NAD-glycohydrolase from the venom of Agkistrodon acutus: regulation of multicatalytic activity. Metallomics 2010, 2:480-489.

23. Prasanth GK, Divya LM, Sadasivan C: Effects of mono and di(n-butyl) phthalate on superoxide dismutase. Toxicology 2009, 262:38-42.

24. Banci L, Bertini I, Blaževitš O, Calderone V, Cantini F, Mao J, Trapananti A, Vieru M, Amori I, Cozzolino M, Carri MT: Interaction of cisplatin with human superoxide dismutase. J Am Chem Soc 2012, 134:7009-7014.

25. Sulkowska A, Bojko B, Równicka J, Sulkowski WW: Paracetamol and cytarabine binding competition in high affinity binding sites of transporting protein. J Mol Struct 2006, 792-793:249-256.

26. Sheng LQ, Zheng XY, Tong HW, Liu SM, Liu QL: Study on interaction between coper lon and Hog liver CuZnSOD by spectroscopy. Acta Chim Sinica 2005, 63:1759-1764.

27. Xu XL, Zhang LY, Shen DK, Wu H, Liu QL: Oxygen-dependent oxidation of $\mathrm{Fe}(\mathrm{II})$ to $\mathrm{Fe}$ (III) and interaction of $\mathrm{Fe}(\mathrm{III})$ with bovine serum albumin, leading to a hysteretic effect on the fluorescence of bovine serum albumin. J Fluoresc 2008, 18:193-201.

28. Shen DK, Xu XL, Wu H, Peng LL, Zhang Y, Song JJ, Su QD: Metal ion binding to anticoagulation factor II from the venom of Agkistrodon acutus: stabilization of the structure and regulation of the binding affinity to activated coagulation factor X. J Biol Inorg Chem 2011, 16:523-537.

29. Li YF, Yang GZ, Mei ZN: Spectroscopic and dynamic light scattering studies of the interaction between pterodontic acid and bovine serum albumin. Acta Pharm Sin B 2012, 2:53-59.

30. Zhang LY, Xu XL, Luo ZF, Zhang Y, Shen DK, Peng LL, Song JJ: Cu(II)- and disulfide bonds-induced stabilization during the guanidine hydrochlorideand thermal-induc- -ed denaturation of NAD-glycohydrolase from the venom of Agkistrodon acutus. Metallomics 2012, 4:166-173. 
31. Markarian SA, Aznauryan MG: Study on the interaction between isoniazid and bovine serum albumin by fluorescence spectroscopy: the effect of dimethylsulfoxide. Mol Biol Rep 2012, 39:7559-7567.

32. Benesi HA, Hildebrand $\mathrm{JH}$ : A spectrophotometric investigation of the interaction of iodine with aromatic hydrocarbons. J Am Chem Soc 1949, 17:2703-2707.

33. Liu $Y$, Xie $M X$, Kang J: Influence of total saponins of panax notoginsengon the conformation of SOD. Acta Chim Sinica 2003, 61:1305-1310.

34. Wu H, Xu XL, Shen DK, Peng LL, Song JJ, Yan Z: Binding of $\mathrm{Ca}^{2+}$ and $\mathrm{Zn}^{2+}$ to factor IX/X-binding protein from venom of Agkistrodon Halys Pallas: stabilization of the structure during $\mathrm{GdnHCl}$ - and thermal-induced denaturation. J Biol Inorg Chem 2011, 16:69-79.

35. Zhang YZ, Zhang XP, Hou HN, Dai J, Liu Y: Study on the interaction between $\mathrm{Cu}(\text { phen })_{3}^{2+}$ and bovine serum albumin by spectroscopic methods. Biol Trace Elem Res 2008, 121:276-287.

36. Cheng ZJ: Interaction of ergosterol with bovine serum albumin and human serum albumin by spectroscopic analysis. Mol Biol Rep 2012, 39:9493-9508.

37. Zhang YZ, Li HR, Dai J, Chen WJ, Zhang J, Liu Y: Spectroscopic studies on the binding of cobalt(II) 1,10-phenanthroline complex to bovine serum albumin. Biol Trace Elem Res 2010, 135:136-152.

38. Hu YJ, Liu Y, Pi ZB, Qu SS: Interaction of cromolyn sodium with human serum albumin: a fluorescence quenching study. Bioorg Med Chem 2005, 13:6609-6614

39. Sheng LQ, Liu SM, Jia LL, Xu XL, Xie RS, Liu QL: The interaction of CuZn-superoxide dismutase and salicylic acid. Chinese J Anal Chem 2003, 31:283-286

40. Zhang YZ, Zhou B, Liu YX, Zhou CX, Ding XL, Liu Y: Fluorescence study on the interaction of bovine serum albumin with P-aminoazobenzene. J Fluoresc 2008, 18:109-118.

doi:10.1186/1752-153X-7-97

Cite this article as: Du et al.: The binding characteristics of isoniazid with copper-zinc superoxide dismutase and its effect on enzymatic activity. Chemistry Central Journal 2013 7:97.

\section{Publish with ChemistryCentral and every scientist can read your work free of charge \\ "Open access provides opportunities to our colleagues in other parts of the globe, by allowing anyone to view the content free of charge." \\ W. Jeffery Hurst, The Hershey Company. \\ - available free of charge to the entire scientific community \\ - peer reviewed and published immediately upon acceptance \\ - cited in PubMed and archived on PubMed Central \\ - yours - you keep the copyright \\ Submit your manuscript here: \\ http://www.chemistrycentral.com/manuscript/<smiles>c1ccccc1</smiles> 